\title{
CARDIAC SYNCOPE IN ATRIAL SEPTAL DEFECT
}

\author{
BY \\ CORNELIO PAPP \\ From the Cardiac Department of the London Chest Hospital
}

Received March 1, 1957

Atrial septal defect (A.S.D.) in adults is often asymptomatic and may be a chance discovery on clinical examination or at mass radiography. Symptoms arise late in the course of the disease and are those commonly seen in other cardiac conditions with right heart failure. Cardiac syncope has not been described as a leading symptom of A.S.D. and must be regarded as a rarity. It may be accidental that within six months of each other two patients came under observation on account of syncope and both had A.S.D. One knew of a cardiac murmur he had since childhood; the other was unaware of any heart disease.

-At a time when surgical repair is becoming a routine procedure in A.S.D., any new symptom has an added interest. This and the different mechanism of syncope in the two cases, caused by coexistent arrhythmia in both, justifies this report.

CASE 1. A man, aged 22, a fitter, had known of his cardiac murmur since childhood and was rejected on account of it from military service when aged 18. He never complained of any shortness of breath, and had been able to run for short distances and climb stairs. His effort tolerance thus has been good if not normal.

In May 1955 he cycled hurriedly to work because he was late. He wanted to make an excuse for his late arrival when he suddenly lost consciousness. The first thing he remembered was lying on the couch in the first-aid room some time later; he did not appear to have had a fit, was not incontinent, and did not injure himself. He went back to work and felt perfectly well. One week later he had a sudden attack of giddiness and fell forward on his outstretched hands, injuring himself; he did not lose consciousness but it took him about ten minutes to recover fully. During the next fortnight he had three similar episodes; during the last one he again lost consciousness and became fully conscious only two hours later at the Casualty Department of a nearby hospital.

From May up to his admission to Charing Cross Hospital in October, 1955, he felt perfectly well.

On examination he was a well-built man with no cyanosis or clubbing. The pulse varied from 80 to 90 ; at times it was regular, at others there were irregularities suggesting extrasystoles. The blood pressure was $120 / 85$.

Clinical examination of the heart showed a right ventricular type of diffuse and tapping cardiac impulse at its normal location. The main finding was a systolic thrill over the pulmonary area; corresponding to this there was a grade III systolic murmur widely heard over the præcordium but loudest over the pulmonary area. The pulmonary second sound was of normal intensity; it was split with delay of the pulmonary component. There were no signs of congestive heart failure; the rest of the examination was normal.

Radioscopy and chest film showed a bulky heart without obvious enlargement; the apex was rounded, the right ventricular conus full, and the main pulmonary artery slightly prominent. In the left oblique position the right ventricle had an increased convexity and the aortic window was obscured by the enlarged left pulmonary branch. The pulmonary vascularity was above average; the pulmonary stem showed increased pulsation but there was no hilar dance; the aorta was small. The cardiogram showed partial right bundle-branch block (Fig. 1.) The diagnosis was that of A.S.D.

After his discharge he took ephedrine gr. $\frac{1}{2}$ twice a day. From November, 1955 to July, 1956 when 


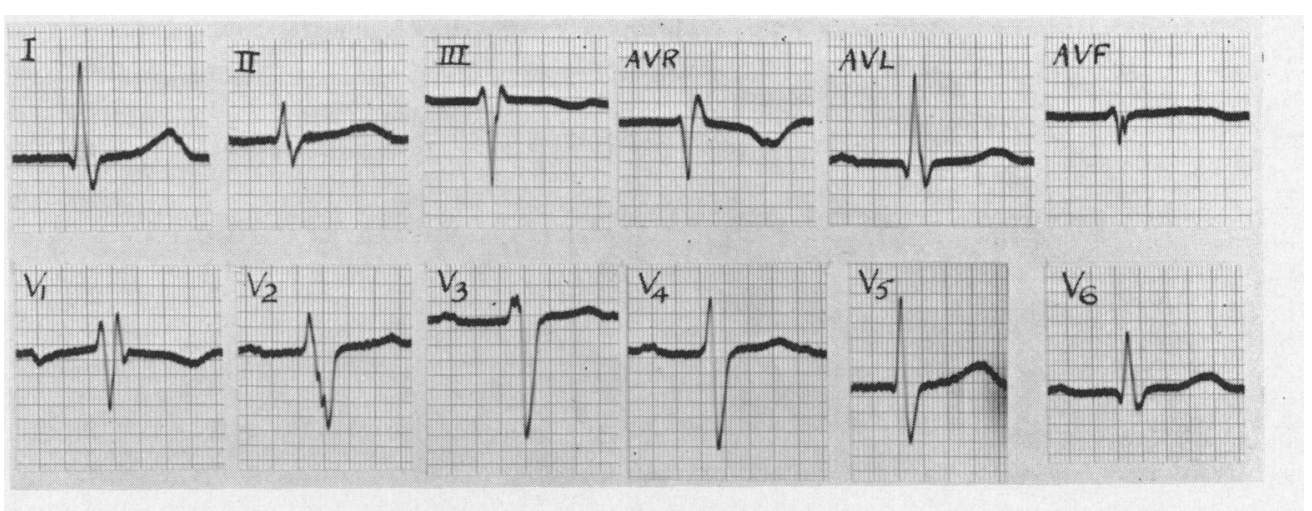

FIG. 1.-Case 1. " $\mathrm{M}$ " complex in V1 the only sign of right ventricular hypertrophy; $P-R$ interval $=0.26 \mathrm{sec}$.

he was admitted to the London Chest Hospital he had only two attacks, the latter on June 12. These were shorter and less severe than those in May, 1955. Though they came suddenly he had a short warning; he felt giddy and had a sickly taste in his mouth. He fell to the ground, not completely unconscious, but unable to move.

The clinical, radiological, and electrocardiographic findings were unchanged. Cardiac catheterization confirmed the clinical diagnosis of A.S.D. with a left-to-right shunt of $7 \cdot 21 . / \mathrm{min}$. (see Table I). No spontaneous syncopal attacks were observed during the stay in hospital, nor could these be provoked by effort, vagal compression, Valsalva manœuvre, or atropine.

TABLE I

Main Cardiac Catheter Data

\begin{tabular}{|c|c|c|c|c|c|c|c|c|c|c|c|c|}
\hline \multirow{4}{*}{ Case } & \multicolumn{4}{|c|}{ Pressure: $\mathrm{mm}$. of $\mathrm{Hg}$} & \multirow{2}{*}{\multicolumn{4}{|c|}{$\begin{array}{c}\text { Oxygen saturation } \\
(\%)\end{array}$}} & \multirow{4}{*}{$\begin{array}{c}\mathrm{A}-\mathrm{V} \\
\mathrm{O}_{2} \text { diff. } \\
\text { Vol. } \\
(\%)\end{array}$} & \multirow{4}{*}{$\begin{array}{l}\text { Pulm. } \\
\text { flow } \\
\text { (1./min.) }\end{array}$} & \multirow{4}{*}{$\begin{array}{c}\text { Syst. } \\
\text { flow } \\
\text { (1./min.) }\end{array}$} & \multirow{4}{*}{$\begin{array}{c}\text { L-R } \\
\text { shunt } \\
\text { (1./min.) }\end{array}$} \\
\hline & \multicolumn{2}{|c|}{$\begin{array}{c}\text { Right } \\
\text { ventricle }\end{array}$} & \multicolumn{2}{|c|}{$\begin{array}{l}\text { Pulmonary } \\
\text { artery }\end{array}$} & & & & & & & & \\
\hline & & & & & SVC & RA & PA & BA & & & & \\
\hline & $\mathrm{S} / \mathrm{D}$ & Mean & $\mathrm{S} / \mathrm{D}$ & Mean & & & & & & & & \\
\hline 1 & $26 / 2$ & 10 & $16 / 5$ & 9 & 73 & 84 & 84 & 93 & $4 \cdot 2$ & $13 \cdot 0$ & $5 \cdot 8$ & $7 \cdot 2$ \\
\hline 2 & $28 / 2$ & 11 & $28 / 7$ & 15 & 62 & 79 & 79 & 91 & 6.0 & $8 \cdot 4$ & $3 \cdot 5$ & 4.9 \\
\hline
\end{tabular}

The Arrhythmia. The cardiograms recorded during the first hospital admission in October 1955, while he was free from syncopal attacks for four-and-a-half months, were all similar. They consisted of periods containing 3-4 P waves and 4-5 $\mathrm{R}$ waves; three of these periods are shown in Fig. 2 ; the lead recorded is V1, where the $\mathrm{P}$ waves were normally inverted. The periods start with a QRS complex which is not preceded by a $P$ wave and is therefore a nodal beat ( $R 1, R 5, R 10)$; this is followed after a varying interval of 0.32-0.37 sec. by a $P$ wave of normal appearance which rides around the peak of the $T$ wave (P1, P4, P8); the next ventricular complex follows after a fixed distance of $0.34-0.32$ sec. (R2, R6, R11). The P-R distance then gradually shortens from 0.24 to 0.18 and to 0.16 and 0.14 and a nodal escape introduces the next period. The $P$ waves follow each other at irregular intervals; after every third or fourth $P$ wave a longer pause follows which in this record is fairly constant $(1.28,1.28,1.28$, and 1.22 sec.) without being a multiple of the previous P-P intervals. Thus there is no sinu-atrial block in the strict sense, but a sinus arrhythmia with periodical sinus standstill. The $\mathrm{R}-\mathrm{R}$ distances on the other hand are fairly equal with the exception of the one which follows the nodal escape; the average ventricular rate at 80 a minute is faster than the atrial rate at 62 a minute. This suggests atrio-ventricular dissociation. Ventricular captures occur after every nodal escape and this explains the premature appearance of the 


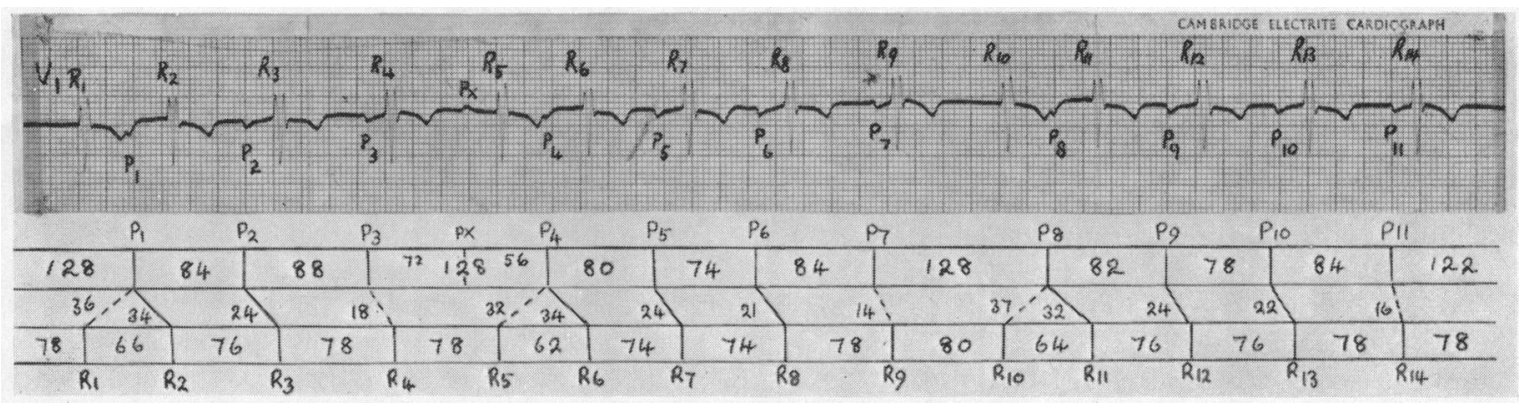

FIG. 2.-Case 1. Electrocardiogram of October, 1955. Lead V1 where P waves were normally inverted. Sinus arrhythmia with sinus standstill, A-V dissociation with interference. Three periods shown consisting of a nodal beat, 1-2 conducted beats, and a dissociated beat. PX=blocked atrial extrasystole separating the first and second period. Full lines $=$ transmitted impulses; interrupted lines $=$ no conduction. Distances in $1 / 100$ of a second. For details see text.

second ventricular complex in every cycle $(\mathrm{R} 2, \mathrm{R} 6, \mathrm{R} 11)$. This is not a reciprocating beat for the $\mathrm{P}$ wave has a normal shape which excludes retrograde conduction; furthermore the $\mathbf{R}-\mathbf{P}$ distance of the nodal escape is variable $(0.36,0.32$ and $0.37 \mathrm{sec}$.) and thus contrasts with the fixed $\mathrm{P}-\mathrm{R}$ distance of the conducted beat $(0.34,0.34,0.32 \mathrm{sec}$.); finally, if atrioventricular dissociation exists there must be uni-directional block which prevents the retrograde spread of the nodal impulse to the atrium. Therefore the upright $\mathbf{P}$ wave which appears half-way between the first and second cycle (PX) and does not interfere with the atrial standstill of the basic rhythm $(1.28 \mathrm{sec}$. $)$ is a blocked atrial extrasystole. P2, P5, P6, P9, P10

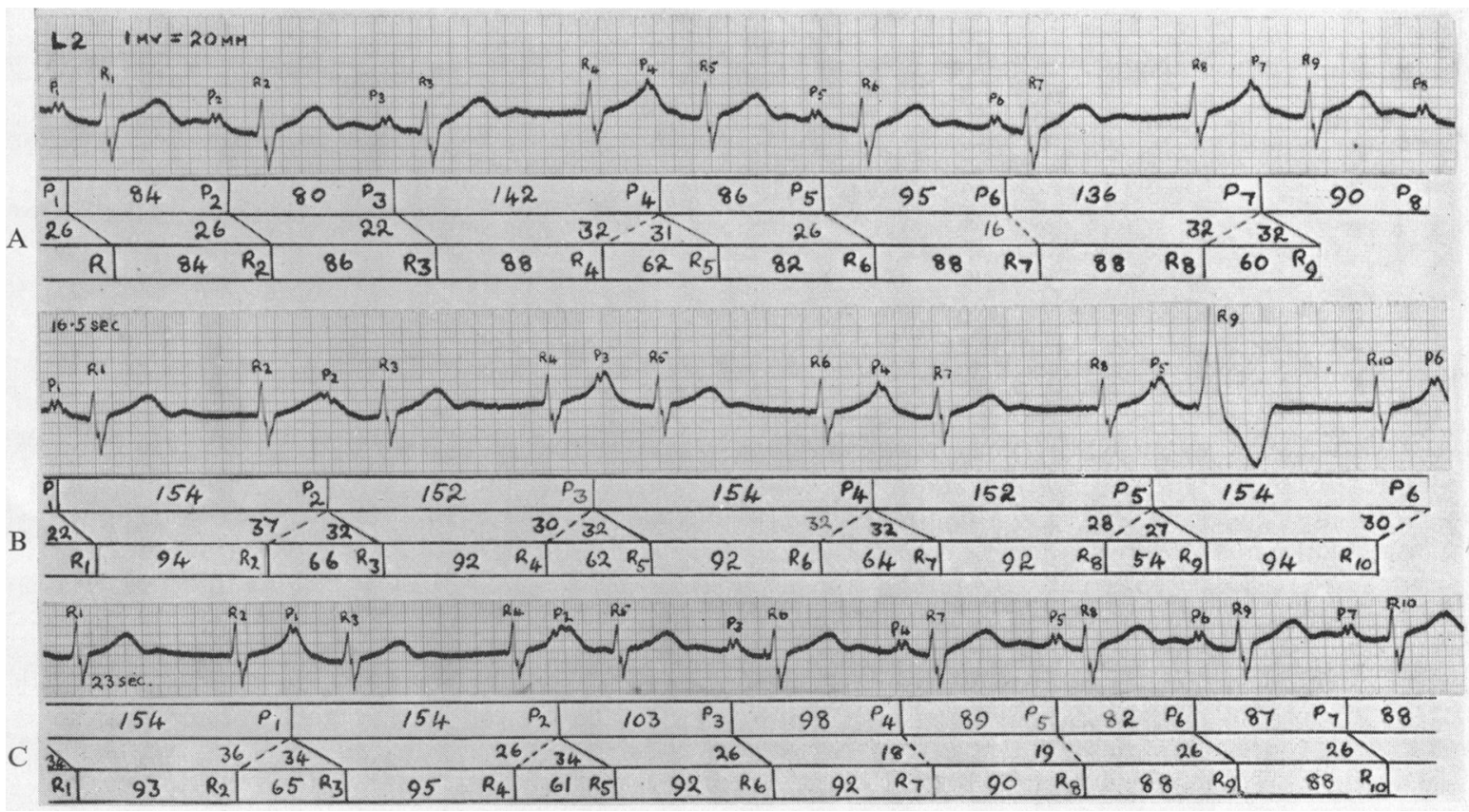

FIG. 3.-Case 1. Electrocardiogram of July, 1956. LII with double standardization shows identical pattern of $P$ throughout. (A) End of effort test. First three cycles show sinus rhythm with $P-R=0 \cdot 26$ sec., followed by period formation as in Fig. 3. (B) $16.5 \mathrm{sec}$. after the end of (A). Sinus bradycardia, atrial rate 39, average ventricular rate of nodal and conducted beats 80 . Coupled rhythm formed by nodal and conducted beats persists for $26.5 \mathrm{sec}$. during maximal deceleration. (C) $23 \mathrm{sec}$. after the end of (B). At R5 coupling ceases, alternating. sinus rhythm with A-V dissociation for 3 beats, then sinus rhythm as in (A). 
are also conducted to the ventricle for $\mathrm{R} 3, \mathrm{R} 7, \mathrm{R} 8, \mathrm{R} 12$, and $\mathrm{R} 13$ are slightly premature when compared with R4, R5, R9, R10, R14 which appear at the genuine nodal distances of $0.78-0.80 \mathrm{sec}$., representing an inherent nodal rate of 76 a minute. The diagnosis is therefore that of sinus arrhythmia with sinus bradycardia, and atrioventricular dissociation with interference. However, the reason for the syncopal attacks and the prolonged P-R interval of the conducted beats remained obscure until, during an effort test in July, 1956 (when he was admitted for cardiac catheter studies), regular sinus rhythm appeared.

Fig. 3 is from a long strip recorded during an effort test; it shows lead II with double standardization $(1 \mathrm{~m}$. volt $=20 \mathrm{~mm}$.) to enlarge the $P$ waves. The first two beats in $(A)$ are sinus beats with a $P-R$ interval of $0.26 \mathrm{sec}$; this was the constant A-V conduction time during the effort test and no faster conduction was seen at a rate of 90 a minute. Thus during sinus rhythm latent heart block is present. As soon as the rate slows, period formation starts again as in Fig. 2, with the usual sequence of nodal escape, two conducted beats, A-V dissociation, and sinus standstill. (B) is part of the same record 16.5 seconds after the end of (A); suddenly the atrial rate diminishes to 39 a minute. Were it not for the nodal escapes the ventricular rate would be just as slow but the nodal escapes added to the conducted beats keep the ventricles at an average rate of 80 , double the atrial rate. This rhythm persists for 26.5 seconds. R9 shows aberrant interventricular conduction due to its early appearance in diastole. The magnification of the $\mathrm{P}$ waves with double standardization clearly proves that all are of sinus and not of nodal (e.g. retrograde) origin, since their shape remains always the same. At the end of strip (C) recorded 23 seconds after the end of (B) sinus rhythm, with the usual P-R interval of $0.26 \mathrm{sec}$., reappears.

Further electrocardiograms after effort were recorded five months later in November, 1956, when he felt well and had been without cardiac syncope for six months. The records still showed the period formation as seen in Fig. 2, but the periods were longer, contained more conducted beats, and auricular standstill was shorter and variable. During maximal deceleration the atrial rate averaged 60 and the ventricular rate 85 a minute.

Cardiac syncope in this patient was due to periodical sinus bradycardia which still could be produced 18 months after the first syncopal attack by effort, at a time when the nodal automatism, " the ectopic rhythm by default " was fully effective. It has to be remembered that he had the first faint after an unusual effort, though subsequently he had them at rest as well. Whether prolonged sinus standstill occurred during these attacks or not is open to speculation. Though retrograde conduction from the nodal beat to the sinus was excluded by the normal $P$ wave the reactivation of the sinus $0.30-0.40 \mathrm{sec}$. after the nodal beat suggests that the latter may have been instrumental in this. The ventricular contraction caused by the nodal impulse may have acted as a mechanical stimulus to the flagging sinus which then continued to function for some beats. Since the length of diastole preceding the nodal beat was almost constant in the single records, it can be presumed that the nodal pacemaker was active all the time, though it was submerged during sinus activity (Lewis, 1925). It is thus conceivable that before nodal automatism was fully developed periods of sinus standstill were responsible for the syncopal attacks, which were then followed by sinus bradycardia and thus produced a state of prolonged semi-consciousness.

CASE 2. A man, aged 58, a painter-decorator, was admitted as an emergency to the Charing Cross Hospital in April, 1956. While washing a wall he became giddy, lost consciousness, fell to the ground, and injured his head. The next thing he remembered was lying on the pavement; he regained consciousness fully about half an hour later in the Casualty Department. On admission he looked pale and was sweating profusely; he had an irregular pulse of 120-140 and a systolic blood pressure of 100 . The provisional diagnosis was that of a silent cardiac infarction.

There had been no significant previous illnesses. He had been active always, though he had noticed some shortness of breath during the past year.

He improved quickly and when transferred to the ward a few hours later the blood pressure rose to $140 / 95$; the pulse rate was 110 , irregular. There was a loud systolic murmur over the lower end of the sternum, a widely split pulmonary second sound, and a short diastolic murmur. There were no signs of congestive heart failure. A chest film showed moderate cardiac enlargement involving the right ventricle and atrium, and enlargement of the pulmonary artery, with overfilling of the pulmonary branches which showed hilar dance on screening. The aorta was small. The cardiogram (Fig. 4) showed 2:1 flutter with right bundle-branch block; there were no signs of cardiac infarction. The diagnosis was atrial septal defect.

Digitalis in high dosage did not restore sinus rhythm nor did it transform the flutter into fibrillation. He was discharged after six weeks, with a 3:1 flutter (A.R.210-V.R.70). 

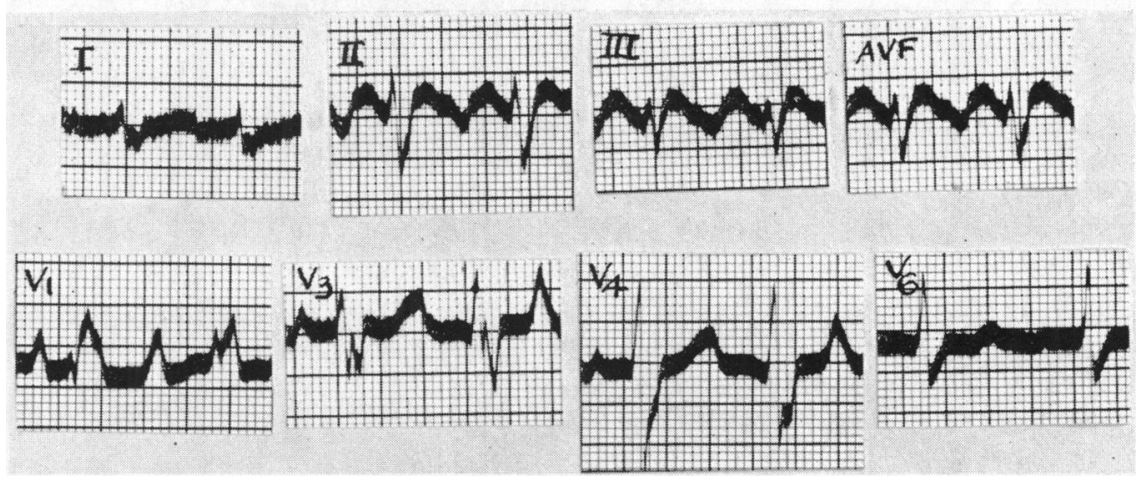

Fig. 4.-Case 2. Electrocardiogram of April, 1956, two days after syncope, showing

2:1 auricular flutter, right bundle-branch block, and right ventricular hypertrophy.

Cardiac catheter studies at the London Chest Hospital three months later confirmed the clinical diagnosis; there was a left-to-right shunt of $51 . / \mathrm{min}$. with normal pressures in the right chambers and pulmonary artery (see Table I). Attempts to restore normal rhythm were again unsuccessful and he was discharged with a $4: 1$ flutter (A.R.232-V.R.58).

When seen in November, 1956, as an outpatient he felt well and had been working in a lighter occupation. There had been no further syncopal attacks, and the 3:1 flutter was kept in control with digitalis.

The syncopal attack in this patient was produced by sudden change of rhythm; the low cardiac output during $1: 1$ or $2: 1$ flutter caused the shock-like state present on admission.

\section{Discussion}

The cause of syncope in both cases was the same, the arrhythmia associated with A.S.D., but the mechanism was different. In Case 1 it was due to impulse inhibition as shown by non-phasic sinus standstill; in Case 2 it was due to rapid impulse formation possibly to $1: 1$ flutter. Since all forms of arrhythmia in A.S.D. are thought to be common (Taussig, 1947) one wonders why syncope is so exceptional. The incidence of arrhythmias in A.S.D. varies in the published series; in the older ones before cardiac catheterization became a common diagnostic procedure they were considered to be frequent. Out of 10 patients coming to necropsy (Bedford et. al., 1941) four had auricular fibrillation and in all these there was associated mitral stenosis. Out of 43 clinical cases only two had auricular fibrillation and one of these had mitral stenosis. In a recent series of A.S.D. comprising 95 cases by Walker et. al. (1956), all proved by cardiac catheter, and of ages ranging from 5 to 40 years, arrhythmias were exceptional and consisted of a few extrasystoles in one and alternating sinus and nodal rhythm in another.

Cardiac arrhythmias in A.S.D. may arise under two different circumstances. Commonly they arise when the disease is progressing, when the atria dilate, and when other predisposing factors such as advancing age and mitral stenosis co-exist. These were the arrhythmias of the older series where the diagnosis was either made at post-mortem examination or when the disease was advanced. The type of arrhythmia was that found in any heart disease, whether congenital or acquired, that involves the atria, i.e. auricular fibrillation or flutter. Case 2, aged 58, is an example.

Rarely auricular arrhythmias are associated with A.S.D. in young people where there is little or no cardiac enlargement, and the cardiogram shows slight right ventricular hypertrophy or only the partial right bundle-branch block. The arrhythmia here is of a complex pattern as in Case 1, or may be of the type of partial heart block (Campbell and Thorne, 1956). These are examples of genuine congenital arrhythmias. Whether they are coincidental with or caused by A.S.D. cannot be decided though the frequent presence of latent heart block in A.S.D. suggests a causal relationship.

Surgical correction was not indicated in either of these patients. The defect was small and the 
shunt amounted to only 30 per cent more than the systemic blood flow. Case 1, a young adult, had no cardiac enlargement and the cardiogram with an $\mathbf{M}$ complex in V1 suggested only a slight degree of right ventricular hypertrophy. Case 2, aged 58, had some cardiac enlargement and signs of incipient heart failure which were easily corrected by digitalis; in view of his age and the persistent flutter, operation was considered too risky. Moreover, the symptoms in both patients were not due to A.S.D. but to the co-existent arrhythmia. The physiological compensatory mechanism of nodal automatism worked satisfactorily in Case 1 and he has not had syncopal attacks for eight months; in Case 2, still in flutter, digitalis maintains a 3:1 block and assures a slow ventricular rate.

\section{SUMMARY}

Cardiac syncope was the only symptom in two cases of atrial septal defect, both with a small shunt. It was caused in the first patient, aged 22, by impulse inhibition through non-phasic atrial standstill, thought to be due to congenital arrhythmia. Compensatory nodal automatism, giving rise to A-V dissociation abolished the attacks. In the second patient, aged 58, syncope was caused by rapid impulse formation through sudden onset of flutter; the arrhythmia here was related to the evolution of the disease and syncope was abolished by reduction of the ventricular rate.

I am greatly indebted to Dr. K. Shirley Smith, Physician to the Cardiac Department for permission to publish these cases under his care. I also wish to thank Dr. Elizabeth A. Priest and Dr. Ronald Gibson for the cardiac catheter data.

\section{REFERENCES}

Bedford, D. E., Papp, C., and Parkinson, J. (1941). Brit. Heart J., 3, 37.

Campbell, M., and Thorne, M. G. (1956). Brit. Heart J., 18, 90.

Lewis, Sir Thomas (1925). The Mechanism and Graphic Registration of the Heart Beat. 3rd ed., Shaw \& Sons, London.

Taussig, H. B. (1947). Congenital Malformations of the Heart. Commonwealth Fund, New York.

Walker, W. J., Mattingly, T. W., Pollock, B. E., Carmichael, D. B., Inmon, T. W., and Forrester, R. H. (1956). Amer. Heart J., 52, 547. 